\title{
The role of inflammation in progression of breast cancer: Friend or foe? (Review)
}

\author{
MICHAEL D. ALLEN and LOUISE J. JONES \\ Centre for Tumour Biology, Barts Cancer Institute, A Cancer Research UK Centre of Excellence, \\ Queen Mary University of London, John Vane Science Centre, London EC1M 6BQ, UK
}

Received April 15, 2015; Accepted May 18, 2015

DOI: $10.3892 /$ ijo.2015.3075

\begin{abstract}
There is a growing interest in the role of the microenvironment in cancer, however, it has been known for over one hundred years that the immune system plays a prominent role in cancer. Recent decades have revealed more and more data on how our own host response to cancer cells can help or hinder progression of the disease. Despite all this work it is surprising how little is known about the role of the immune system in human breast cancer development, as compared to other cancers. Recent successes of PD-1 blockade in treating multiple cancers, and new developments with other immune targets such as CTLA-4 and CSF-1 inhibitors, highlight that it is becoming ever more important that we understand the complexity of the immune and inflammatory systems in the development and progression of breast cancer. With this knowledge it may be possible to not only target therapy but also more accurately predict those patients that truly need it. This review summarises some of the most significant findings for the role of the immune system and inflammatory response in breast cancer progression. Focusing on how the inflammatory microenvironment may be involved in the progression of pre-invasive ductal carcinoma in situ to invasive breast cancer. It will also discuss the use of immune markers as diagnostic and prognostic tools and summarise the state of the art of immune-therapeutics in breast cancer treatment.
\end{abstract}

\section{Contents}

1. Introduction

2. Inflammation as a prognostic indicator

Correspondence to: Dr M.D. Allen, Centre for Tumour Biology, Barts Cancer Institute, A Cancer Research UK Centre of Excellence, Queen Mary University of London, John Vane Science Centre, Charterhouse Square, London EC1M 6BQ, UK

E-mail: m.allen@qmul.ac.uk

Key words: breast cancer, ductal carcinoma in situ, inflammation, progression
3. Tumour associated macrophages

4. Immune surveillance and myeloid derived suppressor cells

5. T-cells

6. B-cells

7. Therapy

8. Conclusion/future directions

\section{Introduction}

Over the past decade there has been a growing need to understand more about the mechanisms involved in the progression of early (pre-invasive) breast cancer [ductal carcinoma in situ (DCIS)] to invasive breast cancer [invasive ductal carcinoma (IDC)]. The breast cancer screening programme is detecting more DCIS than before. Understanding how DCIS progresses will help to tailor therapy and avoid overtreatment, because only $50 \%$ of detected DCIS cases will develop into invasive cancer (1-3).

A significant body of work has focused on unravelling the genetic alterations that occur in cancer cells in the hope of identifying new molecular targets. A study carried out on breast cancer examining normal, atypical ductal hyperplasia (ADH), DCIS and IDC (the traditional view of progression) attempted to show the changes in genetic abnormalities during the development of breast cancer. However, the results demonstrated surprisingly few changes at the various stages, with the greatest number of genetic alterations seen in ADH, which were maintained in DCIS and IDC. The study indicated that the changes to gene expression that occur early in the disease largely reflect those of advanced breast cancer (4). Studies by others have gone on to confirm this hypothesis (5-7). The caveat to this study is that it reflects low-grade disease and therefore may not be relevant to high grade DCIS, HER $2^{+}$and basal types, which have the worst prognosis. Furthermore, the advent of Next Generation Sequencing may reveal more subtle genetic changes associated with disease progression.

This apparent lack of genetic evolution between DCIS and invasive breast cancer has centred attention on the microenvironment in mediating the transition to invasion. This review will focus on the role of the inflammatory cells in progression of DCIS to invasive disease (Table I), for a review of other environmental factors at play see the review by Allen and Jones (8). 


\section{Inflammation as a prognostic indicator}

Since Virchow first observed leukocytes in the stroma of neoplastic tissue in 1863 the immune system has been known to play a role in cancer. The modern paradigm of the role of the tumour microenvironment was further elaborated by Bissell et al (9) and there has since been an explosion of interest, especially in the role of inflammation.

In the 1990's several studies outlined the use of the inflammatory infiltrate in breast cancer as a prognostic marker. Aaltomaa et al examined 489 breast cancer patients with up to 10 years follow-up. They found lymphocyte infiltrate (LI) positively correlated to axillary lymph node status, tumour diameter and histomorphological variables. Multivariate analysis showed that LI was independently related to axillary lymph node status and was able to predict recurrence free survival as well as breast cancer related survival, however this analysis required the proliferation rate to be used in the categorisation of the tumours to be significant (10).

In 1995 Stewart et al noted that mice that develop spontaneous mammary tumours (due to a retroviral driver) have natural killer cell and macrophage infiltrate. They also observed that immune suppression in the pre-malignant phase decreased the incidence of the tumours. They hypothesised that if women have a similar immune promotion paradigm of breast cancer, then women who are therapeutically immune suppressed should demonstrate a lower incidence of breast cancer. They looked at more than 25,000 immune suppressed women, followed for between 1-11 years, and found a significantly lower number of breast cancer cases than expected ( 86 vs. $113, \mathrm{p}=0.009$ ), whereas other cancers exhibited higher incidence (11). This suggested immune promotion plays a significant role in breast cancer initiation and progression.

A more specific study of DCIS was carried out by Lee et al, this study set out to use vascular density as a prognostic indicator for DCIS, at the same time they investigated the contribution of the inflammatory infiltrate, which could affect angiogenesis by release of angiogenic factors and digesting matrix. Angiogenesis is an essential step in progression of breast cancer and the density of the vessels is an important prognostic factor for relapse and overall survival $(12,13)$. Lee $e t$ al stained DCIS cases for a panel of markers (including CD3, CD8, CD45RO, CD45RA, CD20 and CD68). The main pattern of inflammation was B- and T-cells situated adjacent to involved ducts or in the interductal stroma. A less prominent pattern of diffuse stromal infiltrate composed mainly of macrophages (and T-cells to a lesser extent) was also seen. They were able to show an association between increased vascularity around the ducts and the diffuse infiltrate (12). Lee $e t$ al followed up on this study by looking at further markers of inflammatory involvement in DCIS progression. They were able to identify that the enzyme thymidine phosphorylase (TP) is frequently expressed in macrophages, particularly in the perivascular inflammation associated with DCIS. This increase in TP correlated with increased vascularity in DCIS but not in IDC (14).

This study was corroborated by the group of Adrian Harris, albeit in breast cancer, not DCIS. This study demonstrated a significant positive correlation between angiogenesis and macrophages in breast tumours, with highly vascular tumours having higher numbers of macrophages. They went on to show that high focal macrophage infiltration was predictive of worse outcome, reduced relapse free and reduced overall survival albeit in invasive breast carcinoma (15).

The advent of cancer therapies to reactivate anticancer immune responses (mainly via alterations to the T-cell population such as PD-1 inhibition) in lung cancer and melanoma, and studies described below (among others), have focused attention on the predictive importance of tumour-infiltrating lymphocytes (TILs) in breast cancer. In December 2013 a TIL Working Group (16) was convened to establish consensus methodological recommendations for TIL evaluation to aid standardisation across clinical trial design and translation research. The authors suggest this study may lead to the establishment of an immunological grade for breast cancer, which reflects a patient's own antitumour immune response.

\section{Tumour associated macrophages}

Tumour associated macrophages (TAMs) are generated predominantly from peripheral monocytes that traffic to the nascent tumour site (e.g. DCIS) where the factors released by the tumours influence the monocytes to differentiate into macrophages. Macrophages have a plastic phenotype that is highly dependent on the prevalent cytokines and growth factors found in the microenvironment, and the phenotype can change in response to changes in the microenvironment. The scientific community have attempted to define the types of macrophage by classifying them on a spectrum ranging from M1 to M2. Classically activated macrophages (M1) are characterised as pro-inflammatory, secrete cytokines like IL-12 and TNF- $\alpha$ and have tumouricidal activity. Alternative activated macrophages (M2) are characterised as immunosuppressive and express cytokines such as IL-10 and TGF- $\beta$ (17). TAMs exhibit a range of subpopulations, the most well documented are those with an M2 phenotype which express tumour promoting cytokines and growth factors that drive angiogenesis (VEGF), matrix remodelling (MMP2 and MMP9) and immune evasion (TGF- $\beta$ ) (18).

Recently Bögels et al demonstrated that breast cancer cell lines skew macrophages towards an M2 (tumour promoting phenotype), while colon cancer cell lines push macrophages to an M1 (antitumour phenotype). They found differential secretion of proteins by colon and breast cancer cell lines, of which the proteoglycan versican was secreted exclusively by colon carcinoma cell lines. Reducing active versican, by blocking with monoclonal antibodies or shRNA, diminished pro-inflammatory cytokine production by monocytes. They went on to point out that the in vitro observations match with those in patients, where the presence of macrophages in breast or colon carcinomas correlates with poor or good prognosis, respectively (19). This study suggests that different cancers educate the macrophage population differently and that if the macrophages can be re-educated from an M2 to an M1 phenotype this may represent a new therapeutic avenue. This is potentially possible by targeting NF- $\kappa \mathrm{B}$, the key regulator of macrophage phenotype (20).

In breast cancer macrophages are one of the most abundant immune cell types and have been shown to be critical to the development of mammary tumours in mouse models (21). The 
Table I. Summary of inflammatory studies in DCIS and invasive breast cancer.

\section{DCIS}

Presence of $\mathrm{IgG}$ or $\mathrm{M}$ follicles or cells in axillary lymph nodes of DCIS correlates with grade and lymph node metastasis (67).

B-cells

T-cells

Higher nos. of T-reg identify DCIS patients at higher risk of relapse (63).

T-reg marker FOXP3 is linearly associated with progression and metastasis (62).

Macrophages

Association between macrophage infiltrate and vascularity $(12,14)$.
MDSC

Tumour infiltrating lymphocytes (all)
Invasive breast cancer

B-cells in the sentinel and auxiliary nodes correlate with stage and tumour burden (66).

Positive correlation between increased CD20 (B-cells) and higher grade, hormone receptor negativity and basal subtype. Higher number of $\mathrm{CD} 20^{+}$cells correlated with a good prognosis and better survival (69).

Strong association of the expression of B-cell related mRNA transcripts with metastasis-free survival of rapidly proliferating node-negative breast cancer (70).

In rapid proliferating tumours T-cell infiltration correlates with good prognosis (10).

The percentage of CD4 ${ }^{+} \mathrm{T}$-cells positively correlates with metastatic spread and increase tumour size $(55,57)$. The level of T-regs in peripheral blood of breast cancer patients correlates with poor prognosis (61).

T-reg marker FOXP3 is linearly associated with progression and metastasis (62).

Total numbers of $\mathrm{CD}^{+} \mathrm{T}$-cells correlate with better patient survival (65).

Positive correlation between angiogenesis and macrophages (15).

Tumours with increased nuclear CSF-1 had more frequent metastasis and poor survival (22).

CCL2/CCL5 expression correlates with advanced stage and progression (26-35,36-38).

Breast cancer cells lines skew macrophages to a tumour promoting phenotype (19).

Increased CD68 staining associates with increased vascularity, nodal metastasis and reduced recurrence free and overall survival $(15,44)$.

Circulating MDSC correlate with cancer stage (53).

MDSC from breast cancer tissue can suppress T-cell responses via IDO (54).

Total lymphocytic infiltration has predictive and prognostic value in HER2 ${ }^{+}$breast cancer (16). Lymphocytic infiltration is a positive prognostic marker in a subset of TNBC $(77,78)$.

HER2 ${ }^{+}$breast cancer with increased lymphocytic infiltration have better response to trastuzumab $(79,80)$.

DCIS, ductal carcinoma in situ; MDSC, myeloid derived suppressor cells; IDO, indoleamine 2,3-dioxygenase; TNBC, triple-negative breast cancer.

mouse model MMTV-PyMT has been observed to exhibit an increase in macrophages in premalignant tissue prior to the angiogenic switch (22). Following on from this, the importance of macrophages in the progression of breast cancer was reported by Scholl et al who demonstrated that tumours with high levels of nuclear CSF-1 (a macrophage growth and recruitment factor) had more frequent metastases and this correlated with poor survival (23). Lin et al were able to mutate the CSF-1 gene in PyMT mice, this had the effect of reducing the macrophage infiltrate at the tumour site and inhibited the angiogenic switch, delaying tumour progression (24). By overexpressing CSF-1 in a transgenic model they were able to demonstrate robust angiogenesis, even at premalignant stages, due to premature macrophage infiltration (13). More recently DeNardo et al 
have demonstrated that blocking the CSF-1 receptor (with a CSF1 mAb or PLX3397, a CSF-1R ATP inhibitor) in combination with paclitaxel treatment improved survival in mammary tumour-bearing mice. The mice exhibited slowed primary tumour development and reduced development of high grade carcinomas and pulmonary metastasis. This was attributed to the reduced macrophage infiltration and angiogenesis as well as increased CD8 T-cells (25).

Another prominent set of chemokines involved in recruiting TAMs to breast cancer are CCL2 and CCL5. These two chemokines stimulate the migration of monocytes and T-cells and are not normally expressed in breast epithelia. In breast cancer increased expression of CCL2 and CCL5 has been observed and has been correlated with advanced disease and progression (26). Both CCL2 and CCL5 have been shown to stimulate monocyte/macrophage cells to secrete MMP9 and uPA which drive matrix remodelling (27). CCL2 expression in primary breast cancer was shown to have significant prognostic value for relapse free survival and correlated with tumour grade and lack of estrogen and progesterone receptor expression (indicative of poor prognosis) $(28,29)$. Additional smaller studies have shown associations between CCL2 and poor prognosis $(30,31)$.

Because CCL2 is a secreted chemokine the possibility of using it as a serum biomarker for prognostic purposes has been investigated. Several studies have been carried out with varying results, significant differences in the patient cohorts used makes interpreting between the studies difficult. However, some of the studies did detect increased CCL2 serum levels in breast cancer patients with advanced stage cancer (32-34). Study by Qian et al demonstrated that targeting the CCL2/CCR2 axis in tumour cells reduces tumour growth and metastases (35).

High incidence and intensity of CCL5 expression in breast tumour cells correlate with advanced stages of disease (stage II/III vs. stage I) (36) and CCL5 levels in patients with progression, relapse and/or metastasis have been found to be higher than those in remission. CCL5 is also a serum biomarker that is elevated in breast cancer patients when compared to healthy individuals and may correlate with stage (37). It has been shown that CCL5 is a significant predictor of disease progression in stage II patients and using $\mathrm{CCL}^{+} / \mathrm{ER}^{-}$together improves the prediction of disease progression compared to using them alone (38).

CCL5 may potentially be a causative tumour promoting factor in breast cancer, a murine model of breast cancer using 4T1 tumour cells expressing CCL5 antisense exhibited supressed tumour growth and reduced metastasis (39). This is supported by two further studies using CCR5 receptor antagonists, a group from Frances Balkwill's laboratory demonstrated reduced tumour growth of 410.4 murine mammary carcinoma cells with met-CCL5 (40). More recently Velasco-Velazquez et al were able to show the CCR5 receptor antagonists Maraviroc and Vicriviroc reduced in vitro invasion of basal breast cancer cells. In addition Maraviroc decreased pulmonary metastasis of MDA-MB-231 in a mouse model (41).

A key publication from the Weinberg's laboratory (42) has suggested the importance of the microenvironment as the source of CCL5 in breast cancer. It is well known that breast cancer is often accompanied by a desmoplastic response, comprising a variety of stromal cells with pro- and antitumorigenic activities including bone marrow derived mesenchymal stem cells (MSC). They demonstrated human breast cancer cells have the ability to attract human MSCs, using a Transwell assay in which bone-marrow-derived human MSCs were allowed to migrate towards media derived from MCF7/Ras or MDA-MB-231 cultures. It was found that human MSCs migrated much more avidly ( 11 -fold more) towards media derived from these cancer cells than towards non-conditioned media. GFP-labelled human MSCs infused into the venous circulation of mice bearing MCF7/Ras or MDA-MB-231 human breast cancer xenografts localized specifically to the developing tumours, with no observable accumulation in other tissues. Xenograft tumours mixed with MSCs exhibited a marked increase in lung metastases compared to controls. The co-localisation of the MSCs and tumour cells was found to be essential to the increased metastatic phenotype. The authors determined that a paracrine mechanism, the CCL5/CCR5 loop, was driving the effect. MSC cells were found to be producing high levels of CCL5, which was acting on the CCR expressed by breast cancer cells to drive a more motile and invasive phenotype. Knocking down CCL5 in the MSCs or blocking CCR5 on the breast cancer cells was able to reduce the degree of metastasis (42). CCL5 is also associated with the TAM phenotype and has been shown to be upregulated at the RNA level and secreted protein detected in TAM cells derived from mouse sarcomas (43).

Multiple clinical studies have supported TAM measurement in pretreatment biopsies for the prediction of outcome in human breast cancer. Adrian Harris' group have carried out two studies which have demonstrated that increased CD68 levels associate with increased vascularity and nodal metastasis as well as decreased recurrence free and overall survival in human breast cancer $(15,44)$. While Tsutsui et al were able to show that patients with increased TAM density have worse disease free survival (45). More recently Mahmoud et al found that higher total macrophage number was associated with higher tumour grade, ER and PgR negativity, HER-2 positivity and basal phenotype. In univariate survival analysis, higher numbers of CD68 macrophages were significantly associated with worse breast cancer-specific survival $(p<0.001)$ and shorter disease-free interval $(\mathrm{p}=0.004)$. However in multivariate model analysis, the CD68 macrophage count was not an independent prognostic marker. The authors point out that the subsets of macrophages may still be of prognostic use, as these were not determined in their study (46). A study carried out by Jin et al has also demonstrated increased CD $68^{+}$cells in invasive breast cancer and linked this to increased IL-1 $\beta$ expression, which they suggest is (in part) produced by the increased numbers of macrophages. This increase in IL-1 $\beta$ was linked to markers of more aggressive breast cancer. A small increase in IL- $1 \beta$ was seen in DCIS compared to normal tissue but it was not significantly different to benign disease (47).

\section{Immune surveillance and myeloid derived suppressor cells}

There is strong evidence that in some cancers immunesurveillance plays an integral role in initiation, growth and 
response to therapy. The present paradigm is that tumour cells are held in check by the immune system and evasion is required to establish the primary tumour (48). One way tumour cells can evade the immune system is to downregulate their immunogenicity by reducing expression of immunogenic antigens. Another is recruitment of immune suppressor cells, e.g. myeloid derived suppressor cells (MDSC).

MDSCs are a heterogeneous population of bone marrow derived cells (BDMC) including immature macrophages, monocytes, neutrophils and dendritic cells. They function as potent inhibitors of natural killer (NK) cells and T-cells and are critical for the immune escape of tumours. A study with the 4T1 mammary tumour model showed accumulation of granulocytic MDSC correlates with metastatic progression. The MDSCs were found to be potent suppressors of in vitro T-cell proliferation (49). Another study using the 4T1 model by Yang et al demonstrated that MDSC may not only supress the immune response, but actively drive invasion by secreting MMPs at the invasive front (50). Blocking MDSC with zoledronic acid reduces tumour growth and improves antitumour responses in a HER2 breast murine model (51). Additionally, CCL5 has been shown to be important in generation of MDSCs in mice and in humans, CCL5 blocking antibodies have been shown to inhibit MDSCs and drive increased T-cell proliferation (52). In breast cancer patients circulating MDSCs correlate with cancer stage, the highest abundance being found in stage IV patients with metastatic disease (53). MDSCs isolated from breast cancer tissues have been shown to supress T-cell responses via indoleamine 2,3-dioxygenase (IDO) (54).

\section{T-cells}

The extent of T-cell infiltration into invasive breast cancer has been reported to range from $1-45 \%$ of the tumour mass (55). In rapidly proliferating tumours $\mathrm{T}$-cell infiltration correlates with good prognosis, clear auxiliary nodes, smaller tumours, lower grade and better relapse free survival (10). But the type of T-cells present affects progression. A tumour directed immune response involves $\mathrm{CD}^{+}$cytolytic T-cells (Th1) and NK cells, which is protective against the development and progression of a cancer. If the immune response involves the humoral immune response and/or a $\mathrm{CD}^{+}{ }^{+}$(Th2) $\mathrm{T}$-cell population the likely outcome is tumour progression (56). The percentage of $\mathrm{CD} 4^{+} \mathrm{T}$-cells in breast cancer positively correlates with markers of disease progression, including metastatic spread to sentinel nodes and increase primary tumour size $(55,57)$.

The $\mathrm{CD}^{+}{ }^{+} \mathrm{T}$-cells with a suppressive phenotype have been studied for some decades and have been characterised into a subset called regulatory T-cells (T-regs). These play an important role in self-tolerance against auto-immunity and immune homeostasis by repressing a wide variety of immune responses via multiple mechanisms including cell-cell contact and release of soluble factors, e.g. IL-10 and TGF- $\beta$ (56).

In the 4T1 model lung metastasis requires T-reg mediated NK cell inhibition, while depletion of the T-regs reduces lung metastasis (58). Tumour cell expression of galectin-1 is associated with increased T-reg frequency and increased lung metastasis (59). Similarly to MDSC, T-regs have also been show to play an active role in driving invasion, independent of their immunosuppressive function. Gavin et al demonstrated that T-regs can promote lung metastasis of RANK expressing mammary tumours via production of RANK ligand (60).

The levels of T-regs in the peripheral blood of breast cancer patients has been found to be high and tumour infiltrating T-regs levels are higher in breast cancer tissue than normal breast. These higher levels of T-regs correlate with poor prognosis (61). T-regs enriched in FOXP3, GITR and CTLA4 exert the potential to supress effector T-cells in the periphery and are found at high levels in cancer patients, depletion or blockade of this subset can enhance immune protection (56). Gupta et al examined intratumoral expression of FOXP3 in invasive breast cancer compared to DCIS and adjacent tissue; they were able to demonstrate a linear association of intra-tumoural FOXP3 as a marker of progression and metastasis (62). High levels of T-regs have been found to identify breast cancer patients at higher risk of relapse or recurrence and analysis of breast tumours has demonstrated a link between FOXP3 expression and progression of breast cancer $(63,64)$.

Most of the research into the role of T-cells in breast cancer has focused on the immune-suppressive functions, however $\mathrm{CD}^{+}$lymphocytes are a known crucial component of cellmediated immunity. Mahmoud et al set out to determine the prognostic value of tumour-infiltrating $\mathrm{CD}^{+}$cytotoxic lymphocytes in breast cancer. They examined 1,334 unselected breast tumours and found that the total number of $\mathrm{CD}^{+}$cells was positively correlated with tumour grade and inversely correlated with patient's age at diagnosis, ER- $\alpha$ and PgR expression. Total number and distant stromal $\mathrm{CD}^{+}$lymphocytes were associated with better patient survival. In a multivariate analysis, total $\mathrm{CD}^{+} \mathrm{T}$-cell count was an independent prognostic factor for better patient survival. These results suggest that tumour-infiltrating $\mathrm{CD}^{+} \mathrm{T}$ lymphocytes have antitumour activity due to the effect on patient survival (65).

\section{B-cells}

In breast cancer B-cells are found in draining lymph nodes and the tumour stroma, the sentinel nodes are enriched with IgG positive, proliferating B-cells. Studies have shown that the presence of B-cells in the sentinel and auxiliary nodes correlates with disease stage and tumour burden (66). Analysis of the axillary nodes from breast cancers found the presence of IgG positive follicles and/or IgM positive lymphoid cells were statistically related to breast tumours of high grade and $>3$ lymph node metastasis (67). The occurrence of autoantibodies (to smooth muscle or p53) in the serum of cancer patients has been show to correlate with poor prognosis (68). However, more recently Mahmoud et al used immunohistochemistry to investigate the density and localisation of B lymphocytes infiltrating 1,470 breast tumours to identify any prognostic significance and relationship to various clinicopathological factors. There was a positive correlation between higher numbers of total $\mathrm{CD} 20^{+} \mathrm{B}$-cells and higher tumour grade, ER and PgR negativity, and basal phenotype. In univariate survival analysis, higher total number of infiltrating $\mathrm{CD} 20^{+}$cells was associated with significantly better survival, therefore high B-cell numbers correlated with a favourable prognosis independent of the size of the tumour, grade, and lymph node invasion (69). This investigation is supported by the study carried out by Schmidt et al in node negative breast 

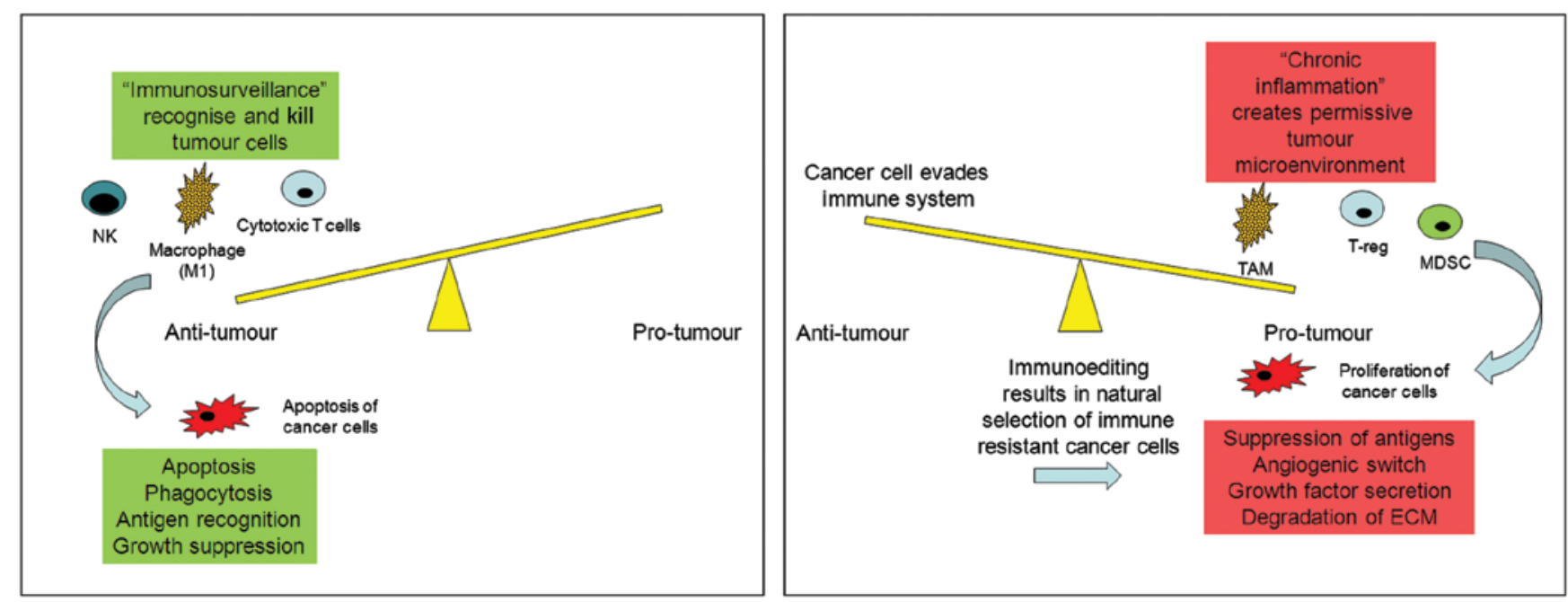

Figure 1. Pro- and antitumour inflammatory cells in the microenvironment. Demonstration of the shifting balance of influence that inflammatory cells are able exert on the tumour microenvironment depending on the relative levels of the different cell types. Dominance of NK cells and cytotoxic T-cells with classically activated macrophages (M1) would lead to tumour killing and a good prognosis. However, increased levels of immunosuppressive MDSC, T-regs and alternatively activated macrophages (TAM) leads to tumour immune evasion, angiogenesis and progression of invasive cancer.

cancer (70). These contradictory studies indicates more work need to be done on the contribution of the humoral response, as Mahmoud et al point out 'there is a distinct lack of data regarding B-cell infiltrate in breast carcinomas using large patient cohorts'. Interestingly, B-cell depletion in mouse models (MMTV-PyMT) has been shown to have no effect on early or late stage mammary carcinogenesis (71), which highlight potential deficiencies in mouse models when studying the complexities of the human immune response to cancer.

\section{Therapy}

Due to immune-surveillance for defective cells solid tumours are often weakly immunogenic and develop strategies to avoid detection by immune cells, such as downregulation of antigenic surface markers (e.g. integrins) and recruitment of immune suppressive cells such as T-Regs and MDSCs (as discussed previously). This has led to the idea that restoration of the immunogenicity or depletion of the immune suppressive cells may enhance the immune system's ability to detect and target cancers (48).

There is increasing evidence that commonly used cytotoxic drugs (e.g. anthracyclins) already increase antitumour immunity and therefore increase their therapeutic effect due to the apoptotic cells triggering antitumour immune signals $(72,73)$. Doxorubicin has been shown to increase tumour antigen specific proliferation of $\mathrm{CD} 8^{+} \mathrm{T}$-cells and biopsies of breast cancer prior to neo-adjuvant therapy showed a correlation between CD8/IFN- $\gamma$ gene expression (indicative of Th1 recruitment) and clinical response to doxorubicin (74). A more comprehensive overview of this area can be read in Criscitiello and Curigliano (75). Subsequently targeted immunotherapies are increasingly being developed, e.g. monoclonal antibodies (mAbs) and tyrosine kinase inhibitors (TKIs). Trastuzumab (mAb targeted to HER2) is the most well-known $\mathrm{mAb}$ in breast cancer treatment, and antibody dependent cell-mediated cytotoxicity (ADCC) has been implicated as a mechanism of action (76).
Screening of H\&E sections for lymphocytic infiltration have been shown to have predictive and prognostic value in triple-negative and HER2 $2^{+}$breast cancer, in this context the TIL Working Group suggests that a strong antitumour immunity directed to multiple targets may result in improved control of a heterogeneous malignant cell population (16). There are some examples of adjuvant and neoadjuvant studies that have examined TILs, full details can be found in the article by Salgado et al (16). Two studies examined TILs in triplenegative breast cancer (TNBC) and hormone receptor positive breast cancer at diagnosis and were found to be a positive prognostic marker in a subset of TNBCs $(77,78)$. Studies of HER $2^{+}$breast cancer and TILs have demonstrated higher TILs in baseline samples or immune enriched resulted in increased response to trastuzumab $(79,80)$.

The T-cell inhibitory molecule B7-H1 (a.k.a. PD-L1) has been shown to induce T-cell anergy when bound to the receptor $\mathrm{PD}-1$. Expression of $\mathrm{PD}-1^{+} / \mathrm{FOXP} 3^{+} \mathrm{T}-$ regs in the breast cancer microenvironment has been demonstrated, raising the possibility of using PD-L1 therapy in breast cancer $(81,82)$. PD-1 is an inhibitory receptor found on activated T- and B-cells, which helps to suppress antitumour immunity (83). The efficacy of PD-1 blockade in the treatment of bladder cancer was recently demonstrated (84), also it has previously been shown that blockade of PD-1 exhibits positive responses in other advanced carcinomas e.g. non-small cell lung carcinoma, melanoma, renal cell carcinoma and ovarian carcinoma (85). There are several active clinical trials currently running investigating the role of anti-PD1 (pembrolizumab) in various cancers. One phase $1 b$ study by Merck (Keynote-012) was recently presented at the San Antonio Breast Cancer Conference 2014 (abstract S1-09) outlining an $18.5 \%$ response to pembrolizumab in PD-L1positive triple-negative breast cancers.

CTLA4 has homology to PD-1, but acts differently to downregulate immune signals and is found on T-cells where it induces T-cell anergy when activated. Phase III trials have demonstrated responses in advanced melanoma either alone (86) or in combination with other drugs (87). There 
are currently several active clinical trials using anti-CTLA-4 (tremelimumab) in different cancers. There has been limited research into the efficacy in breast cancer but one study by Vonderheide et al examined the combination of tremelimumab and exemestane in advanced breast cancer. While the trial was halted due to strong side effects, $42 \%$ of the patients exhibited stable disease for $\geq 12$ weeks and treatment was associated (in most patients) with increased peripheral $\mathrm{CD}^{+}$and $\mathrm{CD}^{+} \mathrm{T}$-cells, and a marked increase in the ratio of inducible costimulator $(\mathrm{ICOS})^{+} \mathrm{T}$-cells to $\mathrm{FOXP}^{+}$regulatory T-cells indicating the treatment was working (88). New targets such as anti-PD-1 and anti-CTLA-4 mAbs may improve outcome in breast cancer, perhaps in combination with standard therapies, e.g. trastuzumab (89).

\section{Conclusion/future directions}

Over the past 20 years much has been learnt about the mechanisms underlying the complex interactions between immune cells and tumour progression. It is generally understood that the way in which the immune system responds to a tumour depends on the type of immune response generated by the microenvironment of that tumour. If a tumour drives $\mathrm{CD}^{+} / \mathrm{Th} 1 \mathrm{~T}$-cells, NK and M1 TAM recruitment, then the tumour progression is likely to be halted and the tumour destroyed or at least severely compromised in its ability to progress. However, if the tumour drives a CD4+/Th2/T-reg, MDSC and M2 TAM response, then the tumour is likely to not only escape immune destruction but the immune cells may actively aid tumour progression to metastasis (Fig. 1). We must bear in mind the caveat that this is an extremely simplified understanding of how the immune system responds to cancer cells and that it is much more complex than this.

The importance of this complexity cannot be underestimated as the immunotherapeutic clinical trials in cancer expand. While the success of the PD-1 inhibitors is an exciting prospect and new investigations into mono and combinatorial treatment for breast cancer are very important, lesson must be learnt from past failures and decreased emphasis must be placed on the reliability of mouse and animal models when making decision about dose, from a toxicity and side effect stand point. It was only 9 years ago, in 2006, that a phase I trial for the drug TGN1412 (the CD28-SuperMaB) resulted in horrific side-effects for the 6 volunteers. It took 6 years to understand how the lack of toxicity in animal models failed to predict the 'cytokine storm' in humans. This failing was a breakdown in the fundamental understanding that laboratory animals are not exposed to infection on a daily basis as are their wild-type counterparts. This difference results in an under-representation of effector T-cells (T-em) vs. T-regs in the laboratory animals compared to the human volunteers. The T-em cells are a reservoir of cytokines stored in tissues waiting to be released which is what happened in the response to treatment with TGN1412 in humans. Other failings were also exposed about the methods of deciding on dose (90). What this study highlights is the need to gain a more comprehensive and detailed understanding of the complexities of the human immune system, which can only be achieved with more research, better animal replacement models and carefully designed clinical trials.
We need to develop a more detailed understanding of how these different cell types interact and use immune cells and cytokines as biomarkers to predict outcome and measure response to therapy. New targets such as anti-PD-1 and anti-CTLA-4 mAbs may improve outcome in breast cancer, perhaps in combination with standard therapies, e.g. trastuzumab (89). Eventually we will be able to harness our own immune system to target and destroy cancers and hopefully immunise patients from relapse.

\section{References}

1. Kerlikowske K, Molinaro AM, Gauthier ML, Berman HK, Waldman F, Bennington J, Sanchez H, Jimenez C, Stewart K, Chew $\mathrm{K}$, et al: Biomarker expression and risk of subsequent tumors after initial ductal carcinoma in situ diagnosis. J Natl Cancer Inst 102: 627-637, 2010.

2. Price P, Sinnett HD, Gusterson B, Walsh G, A'Hern RP and McKinna JA: Duct carcinoma in situ: Predictors of local recurrence and progression in patients treated by surgery alone. Br J Cancer 61: 869-872, 1990.

3. Welch HG and Black WC: Overdiagnosis in cancer. J Natl Cancer Inst 102: 605-613, 2010.

4. Ma XJ, Salunga R, Tuggle JT, Gaudet J, Enright E, McQuary P, Payette T,Pistone M, Stecker K, Zhang BM, et al: Gene expression profiles of human breast cancer progression. Proc Natl Acad Sci USA 100: 5974-5979, 2003.

5. Castro NP, Osório CA, Torres C, Bastos EP, Mourão-Neto M, Soares FA, Brentani HP and Carraro DM: Evidence that molecular changes in cells occur before morphological alterations during the progression of breast ductal carcinoma. Breast Cancer Res 10: R87, 2008.

6. Moelans CB, de Weger RA, Monsuur HN, Maes AH and van Diest PJ: Molecular differences between ductal carcinoma in situ and adjacent invasive breast carcinoma: A multiplex ligationdependent probe amplification study. Anal Cell Pathol (Amst) 33: $165-173,2010$.

7. Solin LJ, Gray R, Baehner FL, Butler SM, Hughes LL, Yoshizawa C, Cherbavaz DB, Shak S, Page DL, Sledge GW Jr, et al: A multigene expression assay to predict local recurrence risk for ductal carcinoma in situ of the breast. J Natl Cancer Inst 105: 701-710, 2013.

8. Allen M and Jones LJ: Jekyll and Hyde: The role of the microenvironment on the progression of cancer. J Pathol 223: 162-176, 2011.

9. Bissell MJ, Hall HG and Parry G: How does the extracellular matrix direct gene expression? J Theor Biol 99: 31-68, 1982.

10. Aaltomaa S, Lipponen P, Eskelinen M, Kosma VM, Marin S, Alhava $\mathrm{E}$ and Syrjänen K: Lymphocyte infiltrates as a prognostic variable in female breast cancer. Eur J Cancer 28A: 859-864, 1992.

11. Stewart T, Tsai SC, Grayson H, Henderson R and Opelz G: Incidence of de-novo breast cancer in women chronically immunosuppressed after organ transplantation. Lancet 346: 796-798, 1995.

12. Lee AH, Happerfield LC, Bobrow LG and Millis RR: Angiogenesis and inflammation in ductal carcinoma in situ of the breast. J Pathol 181: 200-206, 1997.

13. Lin EY, Li JF, Gnatovskiy L, Deng Y, Zhu L, Grzesik DA, Qian H, Xue XN and Pollard JW: Macrophages regulate the angiogenic switch in a mouse model of breast cancer. Cancer Res 66: 11238-11246, 2006.

14. Lee AH, Dublin EA and Bobrow LG: Angiogenesis and expression of thymidine phosphorylase by inflammatory and carcinoma cells in ductal carcinoma in situ of the breast. J Pathol 187: 285-290, 1999.

15. Leek RD, Lewis CE, Whitehouse R, Greenall M, Clarke J and Harris AL: Association of macrophage infiltration with angiogenesis and prognosis in invasive breast carcinoma. Cancer Res 56: 4625-4629, 1996.

16. Salgado R, Denkert C, Demaria S, Sirtaine N, Klauschen F, Pruneri G, Wienert S, Van den Eynden G, Baehner FL, PenaultLlorca F, et al: The evaluation of tumor-infiltrating lymphocytes (TILs) in breast cancer: Recommendations by an International TILs Working Group 2014. Ann Oncol 26: 259-271, 2015. 
17. Biswas SK and Mantovani A: Macrophage plasticity and interaction with lymphocyte subsets: Cancer as a paradigm. Nat Immunol 11: 889-896, 2010.

18. Tang X: Tumor-associated macrophages as potential diagnostic and prognostic biomarkers in breast cancer. Cancer Lett 332 3-10, 2013

19. Bögels M, Braster R, Nijland PG, Gül N, van de Luijtgaarden W, Fijneman RJ, Meijer GA, Jimenez CR, Beelen RH and van Egmond M: Carcinoma origin dictates differential skewing of monocyte function. OncoImmunology 1: 798-809, 2012.

20. Hagemann T, Lawrence T, McNeish I, Charles KA, Kulbe H, Thompson RG, Robinson SC and Balkwill FR: 'Re-educating' tumor-associated macrophages by targeting NF-kappaB. J Exp Med 205: 1261-1268, 2008.

21. Coussens LM and Pollard JW: Leukocytes in mammary development and cancer. Cold Spring Harb Perspect Biol 3: $3,2011$.

22. Guy CT, Cardiff RD and Muller WJ: Induction of mammary tumors by expression of polyomavirus middle $\mathrm{T}$ oncogene: A transgenic mouse model for metastatic disease. Mol Cell Biol 12: 954-961, 1992.

23. Scholl SM, Pallud C, Beuvon F, Hacene K, Stanley ER, Rohrschneider L, Tang R, Pouillart P and Lidereau R: Anticolony-stimulating factor-1 antibody staining in primary breast adenocarcinomas correlates with marked inflammatory cell infiltrates and prognosis. J Natl Cancer Inst 86 : 120-126, 1994.

24. Lin EY, Nguyen AV, Russell RG and Pollard JW: Colonystimulating factor 1 promotes progression of mammary tumors to malignancy. J Exp Med 193: 727-740, 2001.

25. DeNardo DG, Brennan DJ, Rexhepaj E, Ruffell B, Shiao SL, Madden SF, Gallagher WM, Wadhwani N, Keil SD, Junaid SA et al: Leukocyte complexity predicts breast cancer survival and functionally regulates response to chemotherapy. Cancer Discov 1: 54-67, 2011

26. Soria $G$ and Ben-Baruch A: The inflammatory chemokines CCL2 and CCL5 in breast cancer. Cancer Lett 267: 271-285, 2008.

27. Murdoch C, Giannoudis A and Lewis CE: Mechanisms regulating the recruitment of macrophages into hypoxic areas of tumors and other ischemic tissues. Blood 104: 2224-2234 2004.

28. Chavey C, Bibeau F, Gourgou-Bourgade S, Burlinchon S, Boissière $\mathrm{F}$, Laune $\mathrm{D}$, Roques $\mathrm{S}$ and Lazennec $\mathrm{G}$ : Oestrogen receptor negative breast cancers exhibit high cytokine content. Breast Cancer Res 9: R15, 2007.

29. Ueno T, Toi M, Saji H, Muta M, Bando H, Kuroi K, Koike M, Inadera $\mathrm{H}$ and Matsushima K: Significance of macrophage chemoattractant protein-1 in macrophage recruitment, angiogenesis, and survival in human breast cancer. Clin Cancer Res 6 : 3282-3289, 2000.

30. Goede V, Brogelli L, Ziche M and Augustin HG: Induction of inflammatory angiogenesis by monocyte chemoattractant protein-1. Int J Cancer 82: 765-770, 1999.

31. Valković T, Lucin K, Krstulja M, Dobi-Babić R and Jonjić N: Expression of monocyte chemotactic protein-1 in human invasive ductal breast cancer. Pathol Res Pract 194: 335-340, 1998.

32. Dwyer RM, Potter-Beirne SM, Harrington KA, Lowery AJ, Hennessy E, Murphy JM, Barry FP, O'Brien T and Kerin MJ: Monocyte chemotactic protein-1 secreted by primary breast tumors stimulates migration of mesenchymal stem cells. Clin Cancer Res 13: 5020-5027, 2007.

33. Lebrecht A, Grimm C, Lantzsch T, Ludwig E, Hefler L, Ulbrich E and Koelbl H: Monocyte chemoattractant protein-1 serum levels in patients with breast cancer. Tumour Biol 25: 14-17, 2004.

34. Lyon DE, McCain NL, Walter J and Schubert C: Cytokine comparisons between women with breast cancer and women with a negative breast biopsy. Nurs Res 57: 51-58, 2008.

35. Qian BZ, Li J, Zhang H, Kitamura T, Zhang J, Campion LR, Kaiser EA, Snyder LA and Pollard JW: CCL2 recruits inflammatory monocytes to facilitate breast-tumour metastasis. Nature 475: 222-225, 2011.

36. Luboshits G, Shina S, Kaplan O, Engelberg S, Nass D, Lifshitz-Mercer B, Chaitchik S, Keydar I and Ben-Baruch A: Elevated expression of the $\mathrm{CC}$ chemokine regulated on activation normal $\mathrm{T}$ cell expressed and secreted (RANTES) in advanced breast carcinoma. Cancer Res 59: 4681-4687, 1999.

37. Niwa Y, Akamatsu H, Niwa H, Sumi H, Ozaki Y and Abe A: Correlation of tissue and plasma RANTES levels with disease course in patients with breast or cervical cancer. Clin Cancer Res 7: 285-289, 2001
38. Yaal-Hahoshen N, Shina S, Leider-Trejo L, Barnea I, Shabtai EL, Azenshtein E, Greenberg I, Keydar I and Ben-Baruch A: The chemokine CCL5 as a potential prognostic factor predicting disease progression in stage II breast cancer patients. Clin Cancer Res 12: 4474-4480, 2006.

39. Stormes KA, Lemken CA, Lepre JV, Marinucci MN and Kurt RA: Inhibition of metastasis by inhibition of tumor-derived CCL5. Breast Cancer Res Treat 89: 209-212, 2005.

40. Robinson SC, Scott KA, Wilson JL, Thompson RG, Proudfoot AE and Balkwill FR: A chemokine receptor antagonist inhibits experimental breast tumor growth. Cancer Res 63: 8360-8365, 2003

41. Velasco-Velázquez M, Jiao X, De La Fuente M, Pestell TG, Ertel A, Lisanti MP and Pestell RG: CCR5 antagonist blocks metastasis of basal breast cancer cells. Cancer Res 72: 3839-3850, 2012.

42. Karnoub AE, Dash AB, Vo AP, Sullivan A, Brooks MW, Bell GW, Richardson AL, Polyak K, Tubo R and Weinberg RA: Mesenchymal stem cells within tumour stroma promote breast cancer metastasis. Nature 449: 557-563, 2007.

43. Biswas SK, Gangi L, Paul S, Schioppa T, Saccani A, Sironi M, Bottazzi B, Doni A, Vincenzo B, Pasqualini F, et al: A distinct and unique transcriptional program expressed by tumor-associated macrophages (defective NF-kappaB and enhanced IRF-3/STAT1 activation). Blood 107: 2112-2122, 2006.

44. Jubb AM, Soilleux EJ, Turley H, Steers G, Parker A, Low I, Blades J, Li JL, Allen P, Leek R, et al: Expression of vascular notch ligand delta-like 4 and inflammatory markers in breast cancer. Am J Pathol 176: 2019-2028, 2010.

45. Tsutsui S, Yasuda K, Suzuki K, Tahara K, Higashi H and Era S: Macrophage infiltration and its prognostic implications in breast cancer: The relationship with VEGF expression and microvessel density. Oncol Rep 14: 425-431, 2005.

46. Mahmoud SM, Lee AH, Paish EC, Macmillan RD, Ellis IO and Green AR: Tumour-infiltrating macrophages and clinical outcome in breast cancer. J Clin Pathol 65: 159-163, 2012.

47. Jin L, Yuan RQ, Fuchs A, Yao Y, Joseph A, Schwall R, Schnitt SJ, Guida A, Hastings HM, Andres J, et al: Expression of interleukin1beta in human breast carcinoma. Cancer 80: 421-434, 1997.

48. Slaney CY, Rautela J and Parker BS: The emerging role of immunosurveillance in dictating metastatic spread in breast cancer. Cancer Res 73: 5852-5857, 2013

49. Bidwell BN, Slaney CY, Withana NP, Forster S, Cao Y, Loi S, Andrews D, Mikeska T, Mangan NE, Samarajiwa SA, et al: Silencing of Irf7 pathways in breast cancer cells promotes bone metastasis through immune escape. Nat Med 18: 1224-1231, 2012.

50. Yang L, Huang J, Ren X, Gorska AE, Chytil A, Aakre M, Carbone DP, Matrisian LM, Richmond A, Lin PC, et al: Abrogation of TGF beta signaling in mammary carcinomas recruits $\mathrm{Gr}-1^{+} \mathrm{CD} 11 \mathrm{~b}^{+}$myeloid cells that promote metastasis. Cancer Cell 13: 23-35, 2008.

51. Melani C, Sangaletti S, Barazzetta FM, Werb Z and Colombo MP Amino-biphosphonate-mediated MMP-9 inhibition breaks the tumor-bone marrow axis responsible for myeloid-derived suppressor cell expansion and macrophage infiltration in tumor stroma. Cancer Res 67: 11438-11446, 2007.

52. Zhang Y, Lv D, Kim HJ, Kurt RA, Bu W, Li Y and Ma X: A novel role of hematopoietic CCL5 in promoting triple-negative mammary tumor progression by regulating generation of myeloid-derived suppressor cells. Cell Res 23: 394-408, 2013.

53. Diaz-Montero CM, Salem ML, Nishimura MI, Garrett-Mayer E, Cole DJ and Montero AJ: Increased circulating myeloid-derived suppressor cells correlate with clinical cancer stage, metastatic tumor burden, and doxorubicin-cyclophosphamide chemotherapy. Cancer Immunol Immunother 58: 49-59, 2009.

54. Yu J, Du W, Yan F, Wang Y, Li H, Cao S, Yu W, Shen C, Liu J and Ren X: Myeloid-derived suppressor cells suppress antitumor immune responses through IDO expression and correlate with lymph node metastasis in patients with breast cancer. J Immunol 190: 3783-3797, 2013

55. Chin Y, Janseens J, Vandepitte J, Vandenbrande J, Opdebeek L and Raus J: Phenotypic analysis of tumor-infiltrating lymphocytes from human breast cancer. Anticancer Res 12: 1463-1466, 1992.

56. Watanabe MA, Oda JM, Amarante MK and Cesar Voltarelli J: Regulatory T cells and breast cancer: Implications for immunopathogenesis. Cancer Metastasis Rev 29: 569-579, 2010.

57. Kohrt HE, Nouri N, Nowels K, Johnson D, Holmes S and Lee PP Profile of immune cells in axillary lymph nodes predicts diseasefree survival in breast cancer. PLoS Med 2: e284, 2005.

58. Fontenot JD, Gavin MA and Rudensky AY: Foxp3 programs the development and function of $\mathrm{CD} 4{ }^{+} \mathrm{CD} 25^{+}$regulatory T cells. Nat Immunol 4: 330-336, 2003 
59. Bacchetta R, Passerini L, Gambineri E, Dai M, Allan SE, Perroni L, Dagna-Bricarelli F, Sartirana C, Matthes-Martin S, Lawitschka A, et al: Defective regulatory and effector T cell functions in patients with FOXP3 mutations. J Clin Invest 116 1713-1722, 2006.

60. Gavin MA, Torgerson TR, Houston E, DeRoos P, Ho WY Stray-Pedersen A, Ocheltree EL, Greenberg PD, Ochs HD and Rudensky AY: Single-cell analysis of normal and FOXP3-mutant human T cells: FOXP3 expression without regulatory $\mathrm{T}$ cell development. Proc Natl Acad Sci USA 103: 6659-6664, 2006.

61. Li B, Saouaf SJ, Samanta A, Shen Y, Hancock WW and Greene MI: Biochemistry and therapeutic implications of mechanisms involved in FOXP3 activity in immune suppression. Curr Opin Immunol 19: 583-588, 2007.

62. Gupta S, Joshi K, Wig JD and Arora SK: Intratumoral FOXP3 expression in infiltrating breast carcinoma: Its association with clinicopathologic parameters and angiogenesis. Acta Oncol 46 792-797, 2007.

63. Bates GJ, Fox SB, Han C, Leek RD, Garcia JF, Harris AL and Banham AH: Quantification of regulatory $\mathrm{T}$ cells enables the identification of high-risk breast cancer patients and those at risk of late relapse. J Clin Oncol 24: 5373-5380, 2006.

64. Liu Y and Zheng P: FOXP3 and breast cancer: Implications for therapy and diagnosis. Pharmacogenomics 8: 1485-1487, 2007.

65. Mahmoud SM, Paish EC, Powe DG, Macmillan RD, Grainge MJ, Lee AH, Ellis IO and Green AR: Tumor-infiltrating CD8 lymphocytes predict clinical outcome in breast cancer. J Clin Oncol 29: 1949-1955, 2011.

66. Wernicke M: Quantitative morphologic assessment of immunoreactivity in regional lymph nodes of patients with carcinoma of the breast. Surg Gynecol Obstet 140: 919-924, 1975.

67. Urdiales-Viedma M, Nogales-Fernandez F, Martos-Padilla S and Sanchez-Cantalejo E: Breast tumors: Immunoglobulins in axillary lymph nodes. Tumori 72: 575-579, 1986.

68. Tan EM and Shi FD: Relative paradigms between autoantibodies in lupus and autoantibodies in cancer. Clin Exp Immunol 134: $169-177,2003$

69. Mahmoud SM, Lee AH, Paish EC, Macmillan RD, Ellis IO and Green AR: The prognostic significance of B lymphocytes in invasive carcinoma of the breast. Breast Cancer Res Treat 132 545-553, 2012.

70. Schmidt M, Böhm D, von Törne C, Steiner E, Puhl A, Pilch H, Lehr HA, Hengstler JG, Kölbl H and Gehrmann M: The humoral immune system has a key prognostic impact in node-negative breast cancer. Cancer Res 68: 5405-5413, 2008.

71. DeNardo DG, Barreto JB, Andreu P, Vasquez L, Tawfik D, Kolhatkar N and Coussens LM: CD4(+) T cells regulate pulmonary metastasis of mammary carcinomas by enhancing protumor properties of macrophages. Cancer Cell 16: 91-102, 2009.

72. van der Most RG, Currie AJ, Robinson BW and Lake RA: Decoding dangerous death: How cytotoxic chemotherapy invokes inflammation, immunity or nothing at all. Cell Death Differ 15: 13-20, 2008.

73. Zitvogel L, Apetoh L, Ghiringhelli F, André F, Tesniere A and Kroemer G: The anticancer immune response: Indispensable for therapeutic success? J Clin Invest 118: 1991-2001, 2008.

74. Mattarollo SR, Loi S, Duret H, Ma Y, Zitvogel L and Smyth MJ: Pivotal role of innate and adaptive immunity in anthracycline chemotherapy of established tumors. Cancer Res 71: 4809-4820, 2011.

75. Criscitiello $\mathrm{C}$ and Curigliano G: Immunotherapeutics for breast cancer. Curr Opin Oncol 25: 602-608, 2013.

76. Musolino A, Naldi N, Bortesi B, Pezzuolo D, Capelletti M, Missale G, Laccabue D, Zerbini A, Camisa R, Bisagni G, et al: Immunoglobulin $\mathrm{G}$ fragment $\mathrm{C}$ receptor polymorphisms and clinical efficacy of trastuzumab-based therapy in patients with HER-2/neu-positive metastatic breast cancer. J Clin Oncol 26: 1789-1796, 2008.
77. Adams S, Gray RJ, Demaria S, Goldstein L, Perez EA, Shulman LN, Martino S, Wang M, Jones VE, Saphner TJ, et al: Prognostic value of tumor-infiltrating lymphocytes in triple-negative breast cancers from two phase III randomized adjuvant breast cancer trials: ECOG 2197 and ECOG 1199. J Clin Oncol 32: 2959-2966, 2014.

78. Loi S, Sirtaine N, Piette F, Salgado R, Viale G, Van Eenoo F, Rouas G, Francis P, Crown JP, Hitre E, et al: Prognostic and predictive value of tumor-infiltrating lymphocytes in a phase III randomized adjuvant breast cancer trial in node-positive breast cancer comparing the addition of docetaxel to doxorubicin with doxorubicin-based chemotherapy: BIG 02-98. J Clin Oncol 31: 860-867, 2013.

79. Loi S, Michiels S, Salgado R, Sirtaine N, Jose V, Fumagalli D, Kellokumpu-Lehtinen PL, Bono P, Kataja V, Desmedt C, et al: Tumor infiltrating lymphocytes are prognostic in triple negative breast cancer and predictive for trastuzumab benefit in early breast cancer: Results from the FinHER trial. Ann Oncol 25: $1544-1550,2014$

80. Perez EA, Thompson EA, Ballman KV, Anderson SK Asmann YW, Kalari KR, Eckel-Passow JE, Dueck AC, Tenner KS, Jen J, et al: Genomic analysis reveals that immune function genes are strongly linked to clinical outcome in the North Central Cancer Treatment Group n9831 Adjuvant Trastuzumab Trial. J Clin Oncol 33: 701-708, 2015.

81. Ghebeh H, Barhoush E, Tulbah A, Elkum N, Al-Tweigeri T and Dermime S: FOXP $3^{+}$Tregs and $\mathrm{B} 7-\mathrm{H}^{+} / \mathrm{PD}-1^{+} \mathrm{T}$ lymphocytes co-infiltrate the tumor tissues of high-risk breast cancer patients: Implication for immunotherapy. BMC Cancer 8: 57, 2008.

82. Muenst S, Soysal SD, Gao F, Obermann EC, Oertli D and Gillanders WE: The presence of programmed death 1 (PD-1)-positive tumor-infiltrating lymphocytes is associated with poor prognosis in human breast cancer. Breast Cancer Res Treat 139: 667-676, 2013

83. Tumeh PC, Harview CL, Yearley JH, Shintaku IP, Taylor EJ, Robert L, Chmielowski B, Spasic M, Henry G, Ciobanu V, et al: PD-1 blockade induces responses by inhibiting adaptive immune resistance. Nature 515: 568-571, 2014.

84. Powles T, Eder JP, Fine GD, Braiteh FS, Loriot Y, Cruz C, Bellmunt J, Burris HA, Petrylak DP, Teng SL, et al: MPDL3280A (anti-PD-L1) treatment leads to clinical activity in metastatic bladder cancer. Nature 515: 558-562, 2014.

85. Brahmer JR, Tykodi SS, Chow LQ, Hwu WJ, Topalian SL, Hwu P, Drake CG, Camacho LH, Kauh J, Odunsi K, et al: Safety and activity of anti-PD-L1 antibody in patients with advanced cancer. N Engl J Med 366: 2455-2465, 2012.

86. Hodi FS, O'Day SJ, McDermott DF, Weber RW, Sosman JA, Haanen JB, Gonzalez R, Robert C, Schadendorf D, Hassel JC, et al: Improved survival with ipilimumab in patients with metastatic melanoma. N Engl J Med 363: 711-723, 2010.

87. Robert C, Thomas L, Bondarenko I, O'Day S, Weber J, Garbe C, Lebbe C, Baurain JF, Testori A, Grob JJ, et al: Ipilimumab plus dacarbazine for previously untreated metastatic melanoma. N Engl J Med 364: 2517-2526, 2011.

88. Vonderheide RH, LoRusso PM, Khalil M, Gartner EM, Khaira D, Soulieres D, Dorazio P, Trosko JA, Rüter J, Mariani GL, et al: Tremelimumab in combination with exemestane in patients with advanced breast cancer and treatment-associated modulation of inducible costimulator expression on patient $\mathrm{T}$ cells. Clin Cancer Res 16: 3485-3494, 2010.

89. Stagg J, Loi S, Divisekera U, Ngiow SF, Duret H, Yagita H, Teng MW and Smyth MJ: Anti-ErbB-2 mAb therapy requires type I and II interferons and synergizes with anti-PD-1 or antiCD137 mAb therapy. Proc Natl Acad Sci USA 108: 7142-7147, 2011.

90. Hünig T: The storm has cleared: Lessons from the CD28 superagonist TGN1412 trial. Nat Rev Immunol 12: 317-318, 2012. 